\title{
COMBINING ABILITY FOR YIELD OF SOME LINES OF MAIZE SYNTHETIZED IN CONDITIONS OF THE MYZEQE REGION OF ALBANIA
}

\author{
Artan Sota ${ }^{1 *}$, Fetah Elezi $^{2 *}$, Sali Aliu ${ }^{3}$ \\ ${ }^{1 *}$ Agricultural University of Tirana, Faculty of Agronomy and Environment, Department of Plant Production, \\ Tirana, Albania; \\ ${ }^{2 *}$ Agricultural University of Tirana, Institute Plant Genetic Resources, Tirana, Albania; \\ ${ }^{3}$ University of Prishtina, Faculty of Agriculture and Veterinary, Department of Plant Production, Pishtina, Kosovo;
}

${ }^{*}$ Corresponding author Fetah Elezi, e-mail: elezi_fetah@yahoo.com;

Received November, 2018; Accepted December, 2018; Published January, 2019;

DOI: https://doi.org/10.31407/ijees9112

UOI license: http://u-o-i.org/1.01/ijees/81701376

\begin{abstract}
According to Sprague and Tatum (1942), the estimate of combining ability (general and specific) is necessary to effectively exploit the heteroz and synthesis of new hybrids. Sprague and Tatum (1942) defined general combining ability (GCA) as "the average performance of a line in hybrid combinations" and defined specific combining ability (SCA) as "those cases in which certain combinations do relatively better or worse than would be expected on the basis of the average performance of the lines involved". The methods of using these indicators were later elaborated by other authors such as Griffing, Eberhart, Hallauer, etc. This paper gives the results of the estimate of the combining ability for the yield of 15 inbreed lines of the maize selected in Agroarfa Lushnja, Albania. The lines were synthesized by the self-pollination maize hybrid of the class 600, the most widespread hybrid in the Myzeqe region. One of the aims of the work was the evaluation of different hybrids cultivated so that they can be used effectively as a base material in the creation of new maize lines adapted to the conditions of this area. It is known that this region has a dry and hot climate. Selected lines are of six inbreed generations which represent good agronomic indicators as well they resulted the best ones in the testcross analyzer. From the dialel analysis of the combining ability it results that from these hybrids are created four lines of interest for general combining ability and four lines with specific combining ability. Lines 9 and 11 are presented as candidates to enter in the collection of lines that can be used for producing hybrids. From this study it turns out that hybrids that fit well into production conditions can be a good source for creating suitable lines in the conditions of a given area.
\end{abstract}

Key words: Crossing, dialele, general combining ability, specific combining ability. 